\title{
Quantifying the role of ocean coupling in Arctic amplification and sea-ice loss over the 21 st century
}

\author{
Rei Chemke $\mathbb{D}^{1 凶}$, Lorenzo M. Polvani $\mathbb{D i D}^{2,3}$, Jennifer E. Kay ${ }^{4}$ and Clara Orbe ${ }^{2,5}$
}

The enhanced warming of the Arctic, relative to other parts of the Earth, a phenomenon known as Arctic amplification, is one of the most striking features of climate change, and has important climatic impacts for the entire Northern Hemisphere. Several mechanisms are believed to be responsible for Arctic amplification; however, a quantitative understanding of their relative importance is still missing. Here, using ensembles of model integrations, we quantify the contribution of ocean coupling, both its thermodynamic and dynamic components, to Arctic amplification over the 20th and 21st centuries. We show that ocean coupling accounts for $\sim 80 \%$ of the amplification by 2100 . In particular, we show that thermodynamic coupling is responsible for future amplification and sea-ice loss as it overcomes the effect of dynamic coupling which reduces the amplification and sea-ice loss by $\sim 35 \%$. Our results demonstrate the utility of targeted numerical experiments to quantify the role of specific mechanisms in Arctic amplification, for better constraining climate projections.

npj Climate and Atmospheric Science (2021)4:46; https://doi.org/10.1038/s41612-021-00204-8

\section{INTRODUCTION}

One of the most robust responses of the climate system to anthropogenic forcing in climate model projections is Arctic amplification, the greater warming of the Arctic relative to other regions on our planet ${ }^{1}$. Arctic amplification has already been observed over recent decades ${ }^{2,3}$, and has been attributed in part to increased greenhouse gases concentrations ${ }^{4,5}$. This well-known pattern of temperature change not only affects high latitudes ${ }^{1,6,7}$, but also the climate at low and mid-latitudes through the associated Arctic sea-ice loss ${ }^{8-17}$ and changes in poleward heat fluxes ${ }^{18,19}$. In spite of the clear signal of Arctic amplification in recent and coming decades, a quantitative understanding of its underlying mechanisms remains an active area of research.

Previous studies have argued for the importance of several processes in warming of the Arctic and the associated sea-ice loss. For example, on relatively short timescales (intra-seasonal to decadal timescales), changes in the atmospheric circulation, amplified by local feedbacks, were argued to contribute to Arctic amplification and sea-ice loss, mostly during winter, via moisture and heat transport into the Arctic ${ }^{20-24}$. On multi-decadal timescales, ocean-atmosphere-ice coupling, both its thermodynamic (effects of radiative and turbulent surface heat fluxes) and dynamic (effects of ocean heat flux convergence, i.e., ocean heat transport/uptake) components were also argued to play an important role in amplifying the Arctic temperature response: increased absorption of solar radiation due to Arctic sea-ice loss and the positive surface albedo feedback ${ }^{7,25-27}$, changes in longwave radiation including the positive lapse rate feedback in the Arctic and downward fluxes ${ }^{28-32}$, changes in atmospheric circulation and their effect on surface heat fluxes $20,21,23$, and stronger ocean heat transport into the Arctic ${ }^{18,33-35}$.

One of the challenges in studying Arctic Amplification mechanisms is the strong coupling of the climate system components: this makes it difficult, and in some cases impossible, to isolate and separately quantify the relative importance of each of these processes in warming the Arctic. As has been noted by many studies, not only do these processes affect each other, but they are also affected by the Arctic amplification itself, making it difficult to determine the direction of causality, especially when only linear regression and feedback analyses are performed.

In particular, different effects of ocean heat flux convergence on Arctic amplification have been suggested in the recent literature. While several studies suggested that ocean heat flux convergence acts to increase Arctic amplification ${ }^{18,33-38}$, others argued that ocean heat flux convergence acts to slightly oppose it ${ }^{29,39}$, or to have only a minor effect on it ${ }^{40}$, or to actually be a response to $\mathrm{it}^{41}$. The different reported effects of dynamic ocean coupling on Arctic amplification stem in part from the different regions, ocean components and forcings analyzed in the above studies, and in part from relying on regression and feedback analyses alone.

In order to isolate and quantify the different processes that affect Arctic amplification, some studies have conducted locking experiments, where a single process is held fixed and thus cannot contribute to Arctic Amplification ${ }^{28,37,40,42}$. In such studies, the role of a single process is assessed as the difference between simulations with the process active and simulations with the process locked. For instance, a recent cloud-locking study concluded that the impacts of cloud feedbacks on Arctic warming due to increased $\mathrm{CO}_{2}$ are negligible ${ }^{42}$. More directly relevant to this paper, previous fixed-ocean-heat flux convergence studies (i.e., studies that contrasted fully coupled with slab-ocean models) found that, under doubling of $\mathrm{CO}_{2}$ concentrations, ocean heat fluxes (both horizontal and vertical heat transport) act to increase Arctic amplification ${ }^{37,40}$.

Building on such studies, which were confined to an idealized forcing scenario (i.e., abrupt $\mathrm{CO}_{2}$ doubling), we here use a hierarchy of ocean coupling experiments ${ }^{11}$ forced with a realistic transient forcing: the Historical (20th century) and the

\footnotetext{
${ }^{1}$ Department of Earth and Planetary Sciences, Weizmann Institute of Science, Rehovot, Israel. ${ }^{2}$ Department of Applied Physics and Applied Mathematics, Columbia University, New York, NY, USA. ${ }^{3}$ Department of Earth and Environmental Sciences, and Lamont-Doherty Earth Observatory, Columbia University, Palisades, NY, USA. ${ }^{4}$ Cooperative Institute for Research in Environmental Sciences, and Department of Atmospheric and Oceanic Sciences, University of Colorado Boulder, Boulder, CO, USA. ${ }^{5} \mathrm{NASA}$ Goddard Institute for

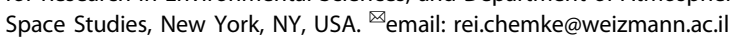


Representative Concentration Pathway 8.5 (RCP8.5, 21st century) scenarios. The hierarchy of ocean coupling experiments allows us to quantify the net role of ocean coupling, and to separate its thermodynamic and dynamic components, in Arctic amplification over the 20th and 21st centuries.

\section{RESULTS}

\section{The role of ocean coupling in Arctic amplification}

We start by considering the Arctic amplification (defined, using the near-surface air temperature, as the difference between the warming of the Arctic region and the warming of the rest of the Earth; the warming is assessed relative to the 1980-1999 period, see Methods) across 38 models of the CMIP5 ensemble (Phase 5 of the Coupled Model Intercomparison Project ${ }^{43}$, Methods) (Fig. 1a). By the end of this century (i.e., over the 2080-2099 period), all CMIP5 models (gray bars) simulate an amplification of the Arctic temperature. CMIP5 models project an Arctic amplification in the range $3.9-7.2 \mathrm{~K}( \pm 1 \sigma)$, with a multi-model mean value of $5.56 \mathrm{~K}$ (green line).

To quantify the role of ocean coupling in Arctic amplification throughout the 20th and 21st centuries, we make use of three ensembles of model integrations of the Community Earth System Model $\left(C E S M 1^{44}\right)$ forced over the 20 th and 21 st centuries with the same Historical and RCP8.5 forcings as CMIP5 (Methods). Each integration is started from a slightly perturbed atmospheric initial condition, resulting in distinct transient behaviors under identical forcing: this allows for the disentangling of the response of the climate system to external forcing from the internally generated climate variability. Averaging across the integrations in each ensemble eliminates much of the internal variability and yields the forced response ${ }^{45}$.

The first large ensemble (hereafter referred to as LE) consists of 40 integrations with the fully coupled model, comprising atmosphere, ocean, land, and sea-ice components ${ }^{46}$. Thus, in LE both thermodynamic and dynamic ocean coupling can affect the warming of the Arctic over the 20th and 21st centuries. The second ensemble, which consists of 20 integrations, is identical to the LE except for its ocean component: in this second ensemble (hereafter referred to as SOM LE), the full physics ocean model is replaced by a slab ocean model (Methods). Note that in the SOM LE the model does include transient changes in thermodynamic coupling (i.e., ocean-atmosphere and ocean-ice heat fluxes) as in the fully coupled LE; however, the ocean heat flux convergence is fixed at preindustrial values (such that that LE and SOM LE are initialized with a very similar preindustrial climatology, see Supplementary Figs. 1 and 2). Thus, since the sole difference between the LE and SOM LE is the presence/absence of changes in mixed-layer ocean heat flux convergence (for simplicity, hereafter referred to as OHFC), comparing the Arctic response in
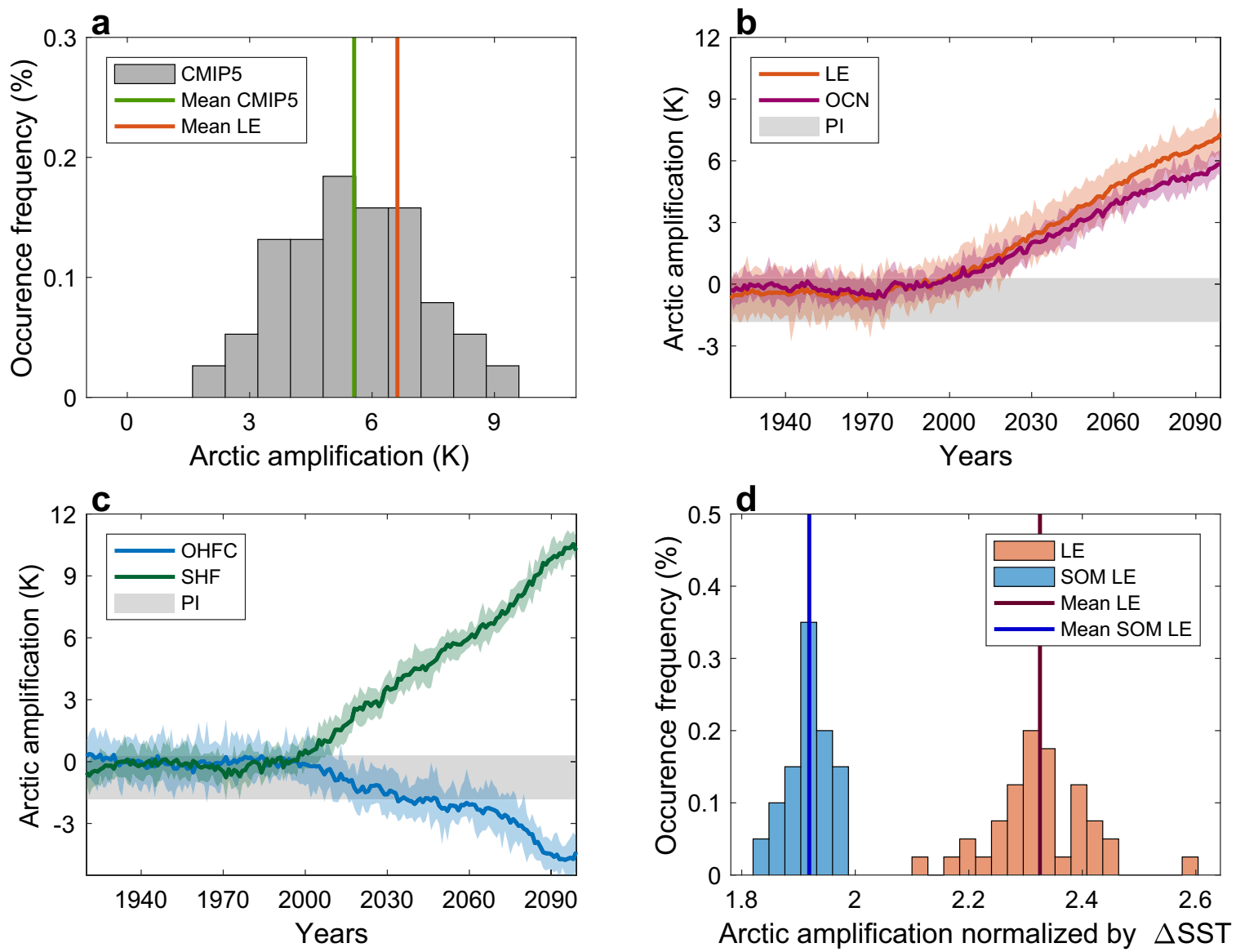

Fig. 1 Arctic amplification and the role of ocean coupling. a The distribution of the projected Arctic amplification (over the last 20 years of the 21st century) across CMIP5 models (gray bars). Green and red lines show Arctic amplification for the CMIP5 mean and LE mean, respectively. $\mathbf{b}$ Evolution of Arctic amplification for the LE mean (red line), and the contribution from ocean coupling (OCN, purple); shading shows the range across the ensemble members. The gray band shows the internal variability $(2 \sigma)$ of Arctic amplification calculated from the preindustrial control run, and centered around the mean preindustrial value. c Decomposing the contribution of ocean coupling into dynamic (OHFC, blue) and thermodynamic (SHF, green) coupling. d The occurrence frequency (in percentage) of the projected Arctic amplification (over the last 20 years of the 21 st century) normalized by the global mean sea surface temperature warming (difference between the last 20 years of the 21 st and 20th centuries) in LE (red) and SOM LE (blue). The red and blue vertical lines show the response for the ensembles mean. 
the LE and SOM LE allows us to isolate and quantify the role of dynamic coupling in Arctic amplification over the 20th and 21st centuries (both the direct effect of OHFC on Arctic amplification, and its indirect effect via other climate system components).

In the third ensemble (hereafter referred to as NOM LE, which also consists of 20 integrations) there is no active ocean model, and the sea surface temperature in the slab ocean model is fixed at preindustrial values (i.e., both dynamic and thermodynamic ocean coupling are fixed). Thus, comparing the Arctic response in LE and NOM LE isolates the role of net ocean coupling (for simplicity, hereafter referred to as OCN), whereas, comparing the response in SOM LE and NOM LE isolates the role of thermodynamic coupling (surface (mixed layer) heat fluxes; for simplicity, hereafter referred to as SHF). Note that the NOM experiment is different from the more common atmosphere-only runs, where both sea surface temperature and sea-ice are prescribed. Here the sea-ice is active in order to solely isolate the role of ocean coupling. Lastly, we note that the smaller ensemble size (of 20 members) in SOM LE and NOM LE is sufficient to quantify the contribution of internal variability to Arctic amplification (Methods, Supplementary Fig. 3).

Before examining the role of ocean coupling, and its different components, in Arctic amplification in these three ensembles, we first ensure that Arctic amplification in the LE is not an outlier within the CMIP5 models, and that the LE adequately captures the observed amplification in recent decades. First, the LE mean shows a projected Arctic amplification similar to the mean CMIP5 (with a value of $6.62 \mathrm{~K}$, as indicated by the red line in Fig. 1a), and is thus well within the value range of most models $(3.9-7.2 \mathrm{~K})$. Second, the evolution of the Arctic amplification from 1920 to 2017 (as computed from the HadCRUT4 ${ }^{47}$ data set, Methods) is well captured by the LE (the black line falls within the red shading in Supplementary Fig. 4). The LE, therefore, can be used for our purpose.

Figure $1 \mathrm{~b}$ shows the evolution across the 20th and 21st centuries of the Arctic amplification in LE (red), and the contribution of net ocean coupling (OCN, purple) to Arctic amplification, along with the Arctic amplification internal variability (in gray, illustrated as two standard deviations from the preindustrial control run, and centered around the mean preindustrial value, Methods). First, by the end of the 20th century ocean coupling accounts for most of the initial warming of the Arctic (compare red and purple lines). As a result, ocean coupling causes the emergence of Arctic amplification from internal variability, which occurs around the year 2000 (when the amplification is first found to be statistically larger than preindustrial values). The large contribution of ocean coupling should not be interpreted as the ocean being the source of the amplification, but rather that ocean-atmosphere and ocean-seaice coupling processes are key for producing the amplification. Furthermore, the role of ocean coupling in warming the Arctic includes both the direct effect of ocean coupling on Arctic amplification, and its indirect effect via other climate system components (e.g., sea-ice, atmospheric circulation, downward longwave radiation, etc.). Second, as the warming increases throughout the 21st century, ocean coupling is again responsible for most of the amplification: it accounts for $\sim 80 \%$ of the amplification by the end of the 21st century.

Decomposing the effect of ocean coupling to thermodynamic (SHF, green) and dynamic (OHFC, blue) coupling (Fig. 1c) reveals that ocean coupling drives the emergence of the amplification via thermodynamic coupling, whereas dynamic coupling contributes negatively, and with a smaller amplitude. It is clear that thermodynamic coupling also drives the amplification throughout the 21 st century (by the end of the 21 st century it produces an amplification of $\sim 10 \mathrm{~K}$, relative to the 1980-1999 period), while dynamic coupling acts to reduce the Arctic amplification (by reducing the Arctic warming more than the warming of the rest of the world); by the end of the 21 st century OHFC reduces the Arctic amplification by $\sim 35 \%$. These opposing roles of thermodynamic and dynamic ocean coupling are present throughout the Arctic, but mostly north of Greenland and the Canadian Archipelago, although the warming effect of net ocean coupling is relatively uniform in the Arctic region (Supplementary Fig. 5).

In spite of the confidence we have in the LE's ability to accurately simulate the recent and projected Arctic amplification, it is conceivable that the mitigating effect of OHFC may be an artifact of the CESM1 model. We thus next qualitatively assess the role of OHFC in Arctic amplification in a different model. Specifically, we compare the Arctic response, relative to preindustrial values, to abrupt $4 \times \mathrm{CO}_{2}$ forcing in fully coupled and slab ocean configurations of the NASA Goddard Institute for Space Studies Model E2.1 (GISS Model E2.1) (Methods, Supplementary Fig. 6). While quadrupling $\mathrm{CO}_{2}$ concentrations is not identical to the Historical and RCP8.5 forcings used in the LE, we qualitatively expect a similar role of OHFC in Arctic amplification, as the $\mathrm{CO}_{2}$ concentrations by the end of the 21st century is approximately quadrupled relative to preindustrial values. Indeed, as in CESM1, we find that OHFC in GISS Model E2.1 reduces the Arctic amplification by $56 \%$ under $4 \times \mathrm{CO}_{2}$ forcing. This suggests that at least the sign of the effect of OHFC, i.e., a considerable reduction in Arctic amplification over the 21st century, is not an artifact of the CESM1 model.

The mitigating effect of OHFC is at odds to the one reported by previous studies, who conducted similar OHFC-fixed experiments under abrupt $2 \times \mathrm{CO}_{2}$ forcing ${ }^{37,40}$ and found that OHFC acts to increase the amplification. This suggests that an abrupt $2 \times \mathrm{CO}_{2}$ forcing might not be strong enough to capture the projected effects of OHFC in the Arctic. To corroborate this we also quantify the role of OHFC in Arctic amplification under an abrupt $2 \times \mathrm{CO}_{2}$ forcing in the GISS Model E2.1 (Supplementary Fig. 6). Indeed, in response to doubling $\mathrm{CO}_{2}$ concentrations, OHFC is found to slightly enhance the Arctic amplification. This emphasizes that in order to correctly assess the role of OHFC in the Arctic climate it is imperative to investigate a realistic transient forcing, or, at least, an idealized forcing of a similar magnitude to one of the future forcing scenarios (e.g., RCP8.5).

\section{The effects of dynamic and thermodynamic ocean coupling}

We now turn to examine the roles of dynamic and thermodynamic coupling in affecting the future Arctic response, and start by recalling that the fixed OHFC in SOM LE comprises both net vertical oceanic heat uptake (i.e., the global mean OHFC) and horizontal heat redistribution by ocean heat transport and nonuniform heat uptake (the difference between OHFC and net heat uptake). To investigate their different roles in the projected Arctic amplification (i.e., over the last 20 years of the 21 st century), we normalize the Arctic amplification by the global mean sea surface temperature response (difference between the 2080-2099 and 1980-1999 periods). The different global mean sea surface temperature response in LE and SOM LE is due to changes in the net oceanic heat uptake (global mean mixed-layer vertical heat transport). Thus, the resulting normalized Arctic amplification in LE vs. SOM LE accounts only for the impacts of horizontal heat redistribution by ocean heat transport. This procedure thus allows us to disentangle the roles of net heat uptake and horizontal heat redistribution; if, for example, net heat uptake has a major (minor) effect on the amplification, then the normalization by the global mean sea surface temperature would have a major (minor) effect on the difference in Arctic amplification between the LE and SOM LE.

The Arctic amplification, over the period 2080-2099, normalized by the global mean surface temperature warming is $\sim 17 \%$ stronger in LE than SOM LE (compare red and blue bars in Fig. 1d): SOM LE mean shows an amplification of 1.9 and LE mean of 
2.3. This result is similar to previous studies who argued that meridional ocean heat transport contributes to Arctic amplification $^{18,33-38}$ (most of the mixed-layer heating from meridional ocean heat flux occurs in the North Atlantic, east of Greenland, rather than in the North Pacific, Supplementary Fig. 7). Since the total OHFC reduces the amplification by $\sim 35 \%$ (Fig. 1b), the relative minor effect of changes in horizontal heat redistribution by ocean heat transport is overcome by the changes in net heat uptake. A similar result can be obtained by redefining the Arctic amplification as the ratio between the Arctic temperature response and the rest of the world surface temperature response. This definition yields a weaker amplification in SOM LE than LE by $\sim 4 \%$ (Supplementary Fig. 8a), emphasizing again that the large effect of the net oceanic heat uptake to reduce the amplification overcomes the relative minor effect of horizontal heat redistribution by ocean heat transport to increase the amplification. In other words, for the same mean surface temperature, the warming of the Arctic is merely the same for SOM LE and LE (Supplementary Fig. $8 b$ ).

To further examine how much of the oceanic heat uptake effect takes place in the Arctic we plot (in Supplementary Fig. 9) the response (differences between the 2080-2099 and 1980-1999 periods) of subsurface Arctic ocean heat content (per unit area) in the mixed layer (red) and deep ocean (blue, defined from the bottom of the mixed layer to the bottom of the ocean). By the end of this century, in the LE mean the deep ocean warms by $7.7 \times 10^{9}$ $\mathrm{Jm}^{-2}$ (blue line), while the mixed layer warms by $1.1 \times 10^{9} \mathrm{Jm}^{-2}$ (red line). Assuming that changes in deep ocean heat content are solely due to oceanic heat uptake (i.e., no meridional heat exchange with lower latitudes in the deep ocean), the latter acts to reduce the mixed layer warming by $\sim 87 \%$. Thus, heat uptake in the Arctic plays an important role in reducing the Arctic amplification.

Next we ask: how does ocean coupling affect Arctic sea-ice loss and polar amplification of atmospheric temperatures? To answer this question we start by investigating the heat exchanges between the atmosphere and the ocean/sea-ice. In particular, we show in Fig. 2 the contribution of surface heat fluxes to the projected surface Arctic amplification (i.e., the difference between the response of surface heat fluxes over the Arctic region and their

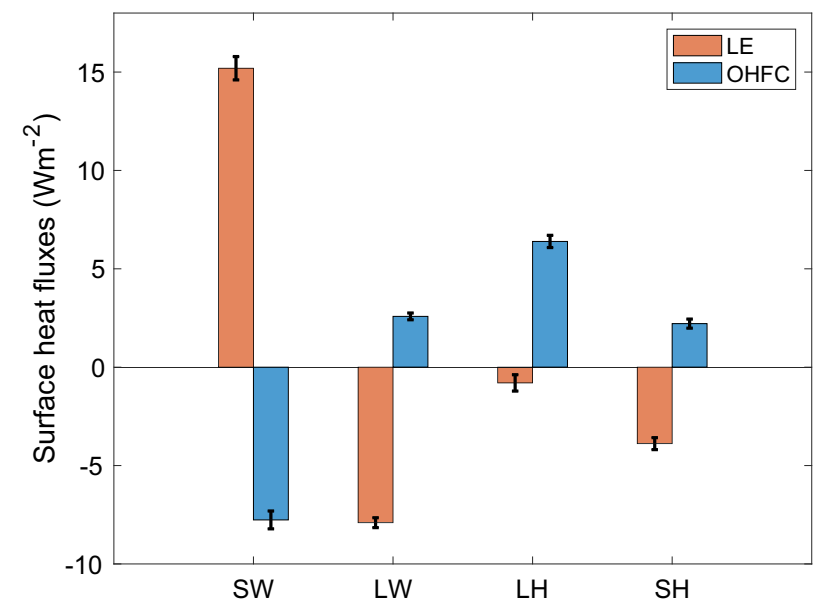

Fig. 2 Future changes in surface heat fluxes. The difference between the response of surface heat fluxes (ocean-atmosphere and sea-ice-atmosphere heat fluxes) over the Arctic $\left(66^{\circ} \mathrm{N}-90^{\circ} \mathrm{N}\right)$, and over the rest of the Earth, decomposed to shortwave (SW) and longwave (LW) radiation, and latent $(\mathrm{LH})$ and sensible $(\mathrm{SH})$ heat components in LE (the fully coupled model, red) and the contribution from OHFC (blue). The response is defined as the differences between the 2080-2099 and 1980-1999 periods. The error bars show one standard deviation across the ensemble members. response over the rest of the Earth; the response is defined as the differences between the 2080-2099 and 1980-1999 periods). We here account for the heat fluxes over both ocean and sea-ice, since ocean thermodynamic and dynamic coupling might affect the atmosphere-sea-ice fluxes via changes in the sea-ice.

First we focus on the surface heat fluxes components in LE (red bars). The shortwave radiative flux (SW) acts to increase the surface warming of the Arctic, which is related to ice-albedo feedback (as shown below). This warming by SW may result in enhanced heat fluxes from the surface to the atmosphere, leading to the Arctic amplification of near-surface air temperature $7,26,27$ (red line in Fig. 1b). Indeed, longwave radiative fluxes (LW), and latent ( $\mathrm{LH})$ and sensible (SH) heat fluxes act to reduce the surface warming of the Arctic in LE as they transfer more heat (and water vapor) away from the surface to the atmosphere in the 21st century, relative to the 20th century, resulting in the Arctic amplification. The spatial patterns of these processes reveal that the relative minor contribution from latent heating to the amplification stems from a cancellation over land and ocean (Supplementary Fig. 10). Note that even after the Arctic becomes ice-free the contribution of thermodynamic coupling to Arctic amplification continues to increase, as the surface continues to warm (Supplementary Fig. 11).

Second, OHFC reduces all surface heat fluxes components (blue bars). The tendency of OHFC to reduce the surface warming effect of SW flux (by $\sim 35 \%$ ), not only suggests that OHFC might also affect the melting of Arctic sea-ice (as shown below), but also that the reduced SW flux supports the OHFC tendency to reduce Arctic amplification: less warming of the surface, via both oceanic heat uptake and the reduced SW flux, might result in less heat transport from the surface to the atmosphere. Indeed, OHFC also reduces the $\mathrm{LW}, \mathrm{LH}$, and $\mathrm{SH}$ fluxes, thus acting to oppose Arctic amplification of near-surface air temperature; OHFC reduces the $\mathrm{LW}$, LH, and SH fluxes by $\sim 25, \sim 90$, and $\sim 35 \%$, respectively (as for the thermodynamic coupling, the effect of dynamic coupling to decrease the amplification continues even after the Arctic becomes ice-free, Supplementary Fig. 11). The reduction in LW, $\mathrm{LH}$, and SH fluxes by OHFC suggests that OHFC might affect the atmospheric temperature response to anthropogenic emissions (as shown below). We next examine the impacts of OHFC and SHF on Arctic sea-ice loss and atmospheric temperature.

Recall that the LE not only adequately captures the observed Arctic amplification, but also the recent observed Arctic sea-ice changes: the LE was shown to accurately simulate the climatological seasonal cycle of Arctic sea-ice extent and its variability, including the spatial distribution of Arctic sea-ice thickness, and the changes in Arctic sea-ice extent over recent decades ${ }^{48-50}$. The evolution of the observed September Arctic sea-ice extent (estimated from the NSIDC data set ${ }^{51}$, Methods) is well captured by the LE (the black line falls within the red shading in Supplementary Fig. 12). This confirms our confidence in using the LE for quantifying the role of ocean coupling in Arctic seaice loss.

To examine the effects of ocean coupling on Arctic sea-ice we start by comparing the evolution of September Arctic sea-ice extent in the LE (red) and the contribution for the time evolution from net oceanic coupling (OCN, purple), thermodynamic coupling (SHF, green), and dynamic coupling (OHFC, blue), along with its internal variability (gray) (Fig. 3). First, not surprisingly, ocean coupling accounts for nearly all changes in Arctic sea-ice (purple line sits on top of the red line). Thus, ocean coupling is responsible for the emergence of sea-ice loss from the internal variability, which occurs around the year 2000 (the emergence of the red and purple lines from the gray region), and the melting of sea-ice throughout the 21 st century.

Second, similar to the evolution of Arctic amplification (Fig. 1c), decomposing the effects of ocean coupling into thermodynamic and dynamic coupling reveals that thermodynamic coupling is 


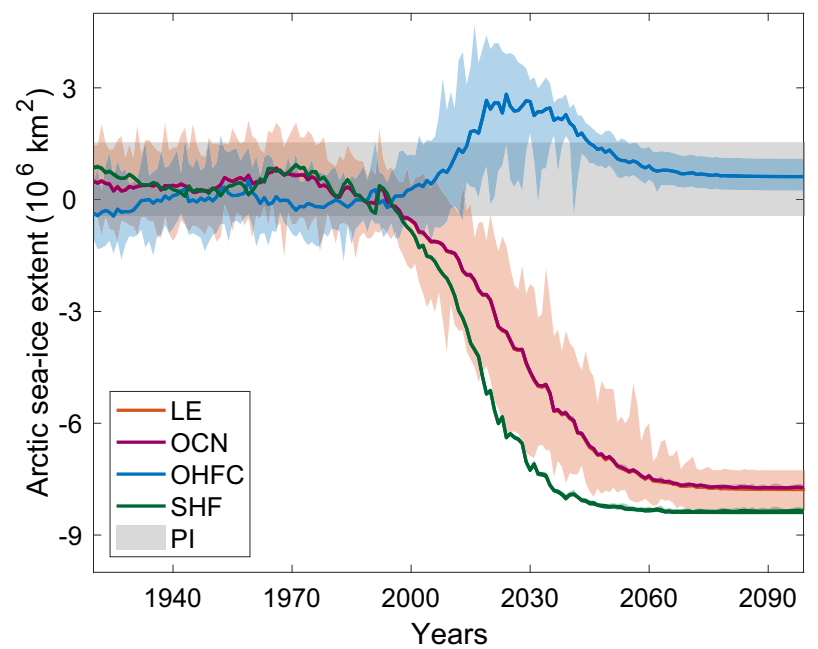

Fig. 3 Evolution of September Arctic sea-ice extent. Time series, relative to the 1980-1999 period, of September Arctic sea-ice extent for the LE mean (red line), the contribution from ocean coupling (OCN, purple line), and decomposing the ocean coupling contribution into dynamic (OHFC, blue) and thermodynamic (SHF, green) components; shading shows the range across the ensemble members. The gray band shows the internal variability (20) of Arctic sea-ice extent calculated from the preindustrial control run, and centered around the mean preindustrial values, relative to the 1980-1999 period.

responsible for both the emergence of sea-ice loss from the internal variability, and the melting of sea-ice throughout the $21 \mathrm{st}$ century: by 2030 SHF results in sea-ice loss of $7.25 \times 10^{6} \mathrm{~km}^{2}$, relative to sea-ice loss of $4.6 \times 10^{6} \mathrm{~km}^{2}$ in LE mean. Dynamic coupling, on the other hand, has a minor effect on the emergence of sea-ice loss, and acts to substantially delay the melting of Arctic sea-ice in the 21 st century: by 2030 OHFC reduces the sea-ice loss by $\sim 35 \%$, thus delaying ice-free conditions by 15 years (defined as the five consecutive years of sea-ice extent $\left.\leq 10^{6} \mathrm{~km}^{21}\right)$. The reduced melting of Arctic sea-ice by OHFC decreases the additional surface warming by SW radiation (via the ice-albedo feedback), and thus also reduces the heat transfer between the surface and atmosphere and the resulting Arctic amplification (Fig. 2). Lastly, the contribution from dynamic coupling shows an interesting evolution that peaks around 2020-2030. One possible explanation for this behavior is that it stems from the tendency of dynamic coupling to damp the sea-ice changes. Assuming that $\frac{\partial S \mathrm{SIE}}{\partial t}=-G(\mathrm{OHFC})$, where SIE is the sea-ice extent and $G$ is the contribution of dynamic coupling to Arctic sea-ice changes, then one would expect the dynamic coupling contribution $(G)$ to peak when the sea-ice changes are largest. Indeed the rate of sea-ice change and the contribution of dynamic coupling exhibit similar evolutions, peaking around the 2020-2030 period (Supplementary Fig. 13).

We next examine the regional impacts of ocean coupling on Arctic sea-ice loss. Figure 4 shows the normalized September Arctic sea-ice response (difference between sea-ice concentrations over the 2020-2040 period and the 1980-1999 period, normalized by the 1980-1999 period) in the mean LE (panel a) and the contribution from OCN (panel b), SHF (panel c), and OHFC (panel d). We choose the 2020-2040 period, rather the last two decades of the 21st century, since there are very low concentrations of seaice by the end of the current century, and the effects of SHF and OHFC on Arctic sea-ice are largest over the 2020-2040 period. In addition, we examine the normalized sea-ice response in order to account for the different reference sea-ice states (i.e., the sea-ice in the 1980-1999 period) in NOM LE, SOM LE, and LE.
In LE most of the melting occurs over the Beaufort sea, the Eastern Arctic seas, and along East Greenland. This melting pattern is largely due to the ocean coupling, and in particular due to thermodynamic coupling. The positive values in Fig. 4d illustrate how OHFC reduces the melting of Arctic sea-ice, notably north of Greenland and the Canadian Archipelago. The opposite effects of SHF and OHFC north of Greenland and the Canadian Archipelago explain the weaker melting over these regions, in comparison to the melting over the Beaufort sea, the Eastern Arctic seas, and along East Greenland seen in the LE mean.

Interestingly, over the same period, the near-surface air temperature response exhibits a relatively uniform warming over the Arctic, which also stems from thermodynamic coupling (Supplementary Fig. 14). The different patterns of near-surface air temperature warming and sea-ice loss suggest that regions where most melting is projected to occur (i.e., over the Beaufort sea, the Eastern Arctic seas, and along East Greenland) might be more sensitive to surface warming. In addition, while ocean coupling plays an important role in future September temperature and sea-ice, September sea level pressure, which is associated with a cyclonic flow over the Arctic, is only weakly affected by ocean coupling, due to the cancellation of thermodynamic and dynamic components (Supplementary Fig. 15).

Lastly, we examine the effect of ocean coupling on atmospheric temperature. Figure 5 shows the response (differences between the 2080-2099 and 1980-1999 periods) of Northern Hemisphere zonal mean atmospheric temperature in the mean LE (panel a) and the contribution from OCN (panel b), SHF (panel c), and OHFC (panel d). A global warming pattern of upper tropical tropospheric warming and polar amplification is evident in LE. Ocean coupling accounts for most of this warming pattern, which is a product of thermodynamic coupling. On the other hand, OHFC also acts to reduce the warming of the entire atmosphere, especially over the Arctic: OHFC reduces the warming by $40-45 \%$ over the Arctic region. This is consistent with the effect of OHFC to reduce the LW, $\mathrm{LH}$, and $\mathrm{SH}$ fluxes from the surface to the atmosphere, and thus Arctic amplification.

\section{DISCUSSION}

Motivated by the desire to explain Arctic amplification, many previous studies have proposed different mechanisms to elucidate the processes responsible for it. In particular, both thermodynamic and dynamic ocean coupling have been shown to affect the Arctic climate, but their effects have not been separately quantified to date under a realistic forcing. This has led, for example, to different reported effects of ocean heat transport/uptake on Arctic amplification. Here, using a hierarchy of ocean configurations, run over the 20th and 21 st centuries, we have quantified the role of ocean coupling, both its thermodynamic and dynamic components, in the Arctic climate response to anthropogenic emissions.

We have shown that, mostly via thermodynamic coupling, ocean coupling accounts for $80 \%$ of the Arctic amplification, and nearly all of the sea-ice loss over the 21 st century. In addition, thermodynamic coupling is responsible for the emergence of Arctic amplification and sea-ice loss from internal variability. On the other hand, dynamic coupling (the effects of ocean heat flux convergence, i.e., ocean heat transport/uptake) has a smaller effect on the Arctic amplification and sea-ice loss over the 20th century, and acts to reduce the Arctic response by $\sim 35 \%$ over the 21 st century. This mitigating effect of ocean heat flux convergence stems from net oceanic heat uptake, which overcomes the relative minor effect of meridional heat redistribution to increase the Arctic amplification. The key role of ocean coupling in the Arctic does not mean that the ocean is solely responsible for the amplification, as other processes (e.g., local radiative feedbacks, 

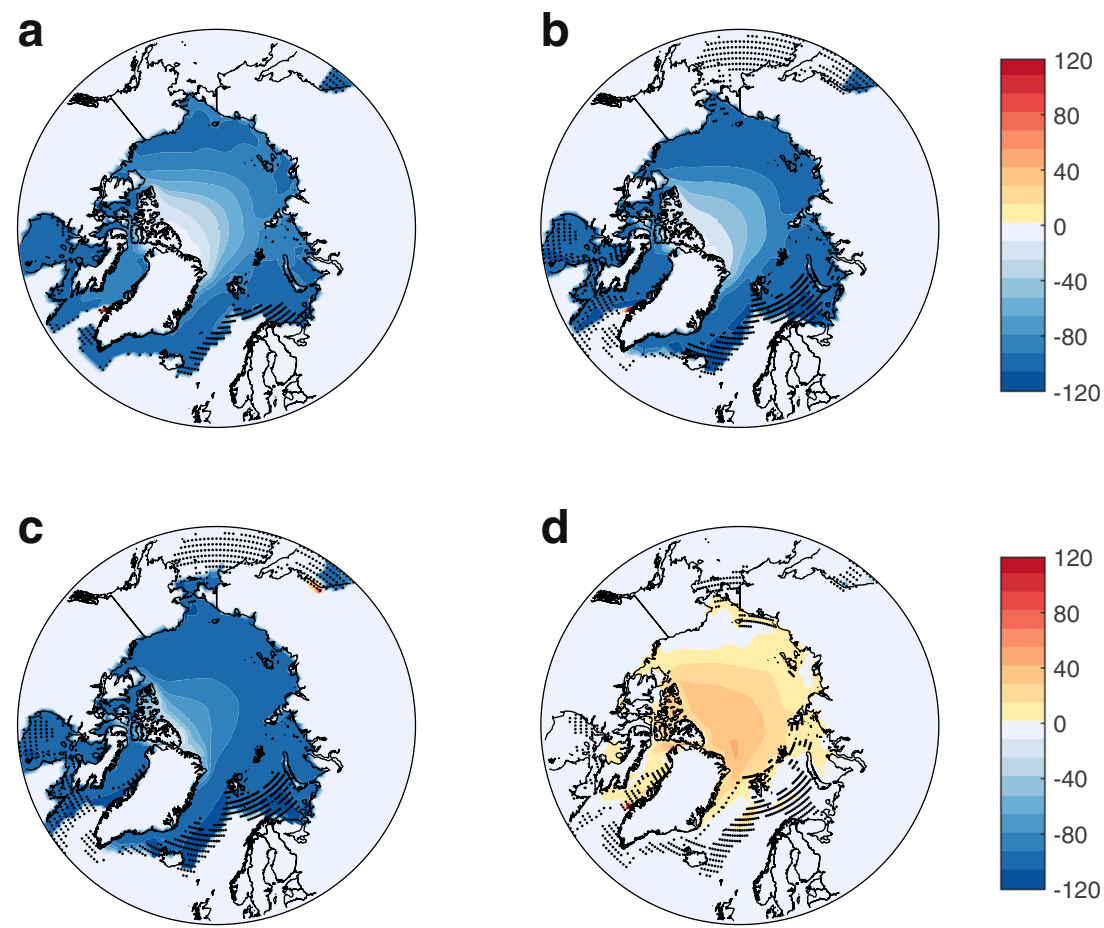

Fig. 4 Regional effects of ocean coupling on September Arctic extent. Response of September Arctic sea-ice concentration (\%, differences between the 2020-2040 and 1980-1999 periods normalized by the 1980-1999 period), in a the LE mean, and the contribution from b net ocean coupling, $\mathbf{c}$ thermodynamic coupling, and $\mathbf{d}$ dynamic coupling. The small black dots show where the differences are statistically insignificant at the $95 \%$ confidence level.
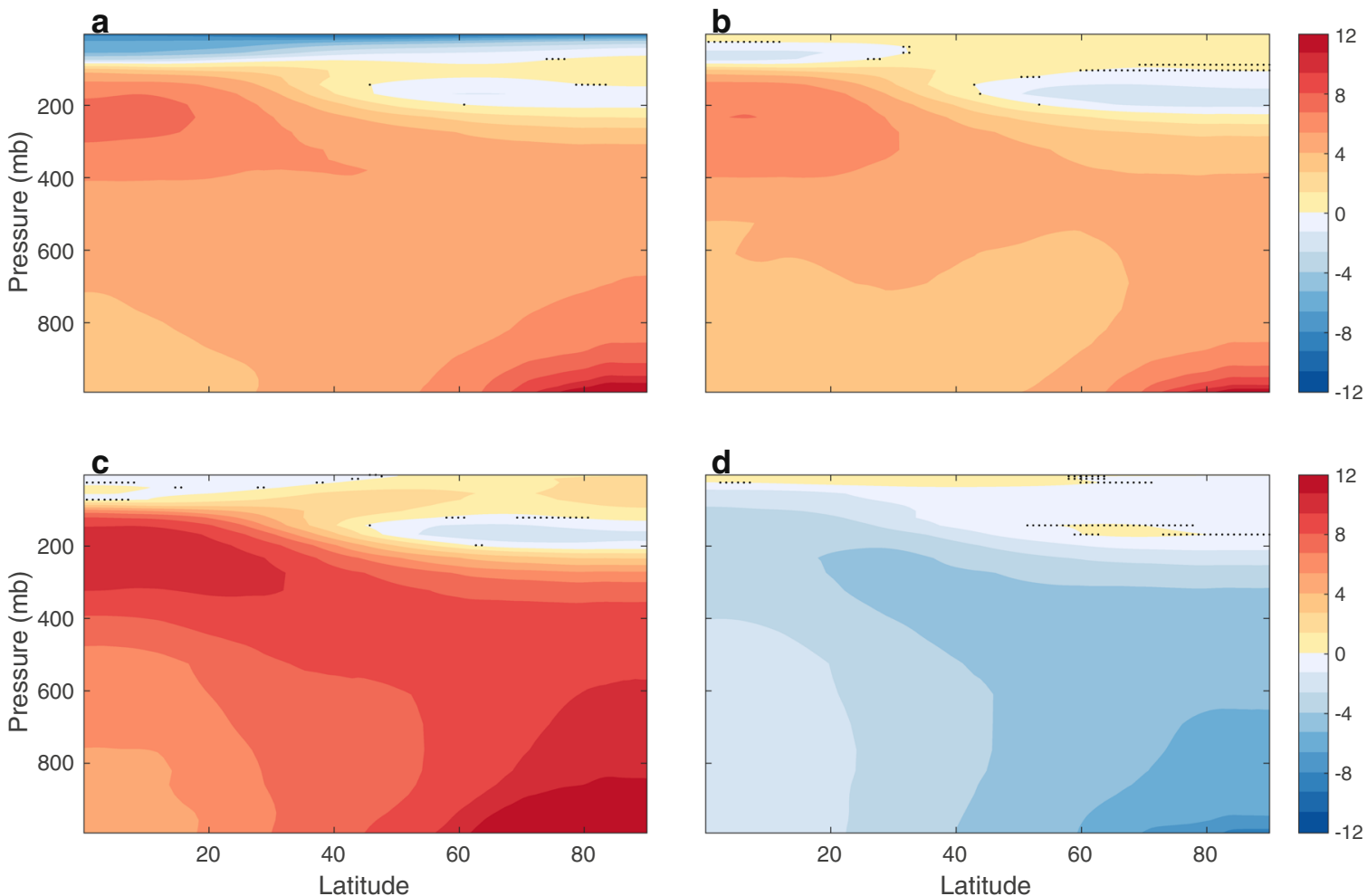

Fig. 5 The effects of ocean coupling on Northern Hemisphere atmospheric temperature. Response (differences between the 2080-2099 and 1980-1999 periods) of the zonal mean atmospheric temperature (K) in a, the LE mean, and the contribution from $\mathbf{b}$ net ocean coupling, c thermodynamic coupling, and d dynamic coupling. The (very few) small black dots show where the differences are not statistically significant at the $95 \%$ confidence level. 
atmospheric circulation, etc.) might affect the warming via ocean coupling processes.

The effect of net oceanic heat uptake to reduce the global surface warming was discussed in earlier studies who emphasized the role of oceanic mixing in delaying global warming ${ }^{52,53}$. For example, under an abrupt increase of $\mathrm{CO}_{2}$ the climate sensitivity was found to be larger in slab ocean configurations than in a fully coupled configurations, due to the role of ocean heat uptake $e^{40,53}$. Thus, the continuously increasing forcing in coming decades suggests that the role of net oceanic heat uptake to reduce the Arctic amplification is expected to continue to increase. Furthermore, since the effect of dynamic coupling on Arctic amplification is less sensitive to surface warming than the effect of thermodynamic coupling (Fig. 1c and Supplementary Fig. 16), under emission scenarios weaker than the RCP8.5, the different roles of thermodynamic and dynamic ocean coupling in Arctic amplification are expected to become more comparable.

It is important to note that while we have here examined the role of ocean coupling in the Arctic temperature and sea-ice response to anthropogenic emissions, ocean coupling also affects the Arctic atmospheric circulation response. Examining the projected annual mean sea level pressure changes by the end of this century reveals that, unlike the minor role of ocean coupling by mid-21st century (Supplementary Fig. 15), net ocean coupling contributes to the increase in sea level pressure over the North Atlantic, and to the decrease over the Eastern Arctic seas, a pattern that enhances a westerly flow over the Arctic (Supplementary Fig. 17). This pattern of sea level pressure occurs because dynamic coupling acts to increase the sea level pressure, mostly around Greenland, whereas the thermodynamic coupling acts to reduce it over the Arctic.

Finally, the important role of dynamic coupling-which significantly reduces the projected Arctic amplification and seaice loss-and thermodynamic coupling - which is responsible for the recent and projected changes in the Arctic-prompt further investigation and monitoring of the Arctic oceanic circulation, heat content, and air-sea heat fluxes. In addition, our results suggest that new locking experiments with other processes (e.g., atmospheric circulation, downward longwave radiation, etc.) that have a large effect on the Arctic response to anthropogenic emissions should be carried out, as this method is central to quantifying the relative importance of different mechanisms causing Arctic amplification. A careful quantification of the relative importance of various mechanisms in the Arctic climate's response to anthropogenic emissions will not only deepen our understanding on human-caused climate change signals, but will also help better constrain climate projections.

\section{METHODS}

\section{Arctic amplification and sea-ice extent}

Arctic amplification is defined as the difference between the warming of the annual mean near-surface air temperature over the Arctic (averaged over $66^{\circ} \mathrm{N}-90^{\circ} \mathrm{N}$ ) and the warming over the rest of the Earth. The warming is assessed relative to the 1980-1999 period. Averaging the Arctic temperature over $75^{\circ} \mathrm{N}-90^{\circ} \mathrm{N}$ yields similar results. This definition of Arctic amplification, based on differences rather than ratios, is chosen in order to avoid dividing by zero in years when the planet as a whole has not warmed; it also allows us to describe the entire evolution of Arctic Amplification over both the 20th and 21 centuries. In addition, defining the Arctic amplification using temperature differences has important implications for the atmospheric and oceanic circulations, which are driven by the meridional temperature gradients. Arctic sea-ice extent is computed by summing the area of all grid cells in the Northern Hemisphere with more than $15 \%$ sea-ice concentrations.

\section{CMIP5 models}

We use monthly data from 38 models that participate in the Coupled Model Intercomparison Project Phase $5^{43}$ (CMIP5), and select only the 'r1i1p1' member between 1850-2099 with the Historical and RCP8.5 scenarios (Supplementary Table 1), in order to weigh all models equally.

\section{CESM1 large ensembles}

Ocean coupling can be investigated via the mixed-layer heat equation,

$\rho c_{p} h \frac{\partial T}{\partial t}=\mathrm{SHF}+\mathrm{OHFC}$,

where, $\rho$ is the sea-water density, $c_{p}$ is the ocean specific heat capacity, $h$ is the mixed layer depth, $T$ is the mixed-layer temperature, SHF represents the net heat flux (radiative and turbulent) into the ocean (i.e., thermodynamic coupling), and OHFC the ocean heat flux convergence $(\nabla \times(\mathbf{v} T)$, dynamic coupling). Note that SHF comprises both ocean-atmosphere heat fluxes and ocean-ice heat fluxes. To study the role of ocean coupling in the Arctic amplification over the 20th and 21st centuries we use three ensembles of model simulations that isolate the roles of the different components in Eq. (1). These are carried out with the state-of-the-art Community Earth System Model $\left(\mathrm{CESM}^{44}{ }^{44}\right.$, which comprises atmosphere, ocean, land, and sea-ice components with about $1^{\circ}$ horizontal resolution. The first ensemble uses the full CESM1 configuration (LE), and consists of 40 members running from 1920-2099 under the same Historical (through 2005) and the RCP8.5 (through 2099) forcing as for the CMIP5 models. In this ensemble both changes in thermodynamic and dynamic coupling can affect the climate's transient response to external forcing. The first member in the ensemble is initialized from a preindustrial control run, and the other members branch off the first member at year 1920, with a minor change in air temperature $\left(\mathcal{O}\left(10^{-14}\right) K\right)^{46}$, which, due to the chaotic nature of the system, leads to distinct transient behaviors across the members. The spread across the members allows one to compute the system's forced response to external forcing, since by averaging across the different members one almost eliminates the internal variability.

The second ensemble consists of 20 simulations integrated from 1920-2099 under the same Historical and RCP8.5 forcing, and has the exact same model configuration as the first ensemble, except for the fullphysics ocean component which is replaced with a slab ocean model (SOM LE). As in the LE, the first member in SOM LE is initialized from the SOM preindustrial run, and the other members branch off the first member at year 1920. The slab ocean includes changes in ocean-atmosphere and ocean-sea-ice thermodynamic coupling, but not in dynamic coupling: the OHFC in the slab ocean model, is fixed at preindustrial values. Thus, taking the difference between the transient behavior in the mean LE and SOM LE allows one to isolate and quantify the role of OHFC in the climate's transient response: the sole difference between the two ensembles is the presence/absence of changes in both horizontal heat transport and oceanic heat uptake. Note that not only OHFC is fixed at preindustrial values but also the mixed layer depth. Thus, the difference between the mean LE and SOM LE also accounts for vertical heat transport processes within the mixed-layer, i.e., changes in the mixed-layer heat capacity due to turbulent mixing. A smaller number of members in the SOM LE is sufficient for capturing the variability since the lack of changes in OHFC reduces the internal variability in this slab ocean configuration. While Arctic amplification variability in the LE is nearly the same (captures $99 \%$ of the variability) for an ensemble size larger than 13 members, in the SOM LE, the variability is nearly the same for an ensemble size larger than 7 members (Supplementary Fig. 3).

The third ensemble also consists of 20 simulations integrated over the 20th and 21st centuries under the same Historical and RCP8.5 forcing. It uses the same slab ocean model as in SOM LE, only here the sea surface temperature is fixed at preindustrial values (i.e., both oceanic dynamic and thermodynamic coupling are fixed). Thus, as there is no active ocean model in this ensemble (NOM LE), comparing the transient behavior in the LE and NOM LE allows one to isolate and quantify the role of net ocean coupling (both oceanic dynamic and thermodynamic) in the climate's transient response. In addition, taking the difference between the mean SOM LE and NOM LE isolates the role of thermodynamic coupling (SHF; the impacts of ocean-atmosphere and ocean-ice heat fluxes on the mixedlayer temperature). Similar to the $L E$, in the NOM LE, the variability of Arctic amplification is nearly the same for an ensemble size larger than 14 
members (Supplementary Fig. 3), and thus the NOM LE ensemble size is sufficiently large for capturing the variability.

Finally, it is important to initialize all ensembles from the same preindustrial climatology in order to ensure that their different transient behaviors are only due to changes in ocean processes, and not due to different background states. Thus, the monthly OHFC and annual mixedlayer depth used in SOM LE, and the sea surface temperature used in NOM LE are computed using the OHFC, mixed layer depth, and sea surface temperature climatology from 1100 years of the preindustrial run of the fully coupled model ${ }^{54}$, to ensure the same preindustrial climatology (Supplementary Figs. 1 and 2). The preindustrial run with the fully coupled CESM1 configuration is 1800-years long with constant 1850 forcings, and thus all time-dependence is due only to the internal climate variability ${ }^{46}$.

\section{Observations}

The observed surface air temperature (1880-2017) is taken from the HadCRUT4 ${ }^{47}$ data set, which uses a combination of satellite and in-situ measurements to produce monthly means of global surface temperature over land and ocean. The observed sea-ice extent is taken from the National Snow and Ice Data Center (NSIDC ${ }^{51}$ ), which uses satellite-based multichannel passive-microwave data to produce monthly mean of sea-ice extent.

\section{GISS ModelE}

We also compare the Arctic response to anthropogenic emissions in the fully coupled and slab ocean configurations of the NASA Goddard Institute for Space Studies ModelE E2.1 ${ }^{55}$. In particular, we examine the response (last 40 years of 150-year and 60-year fully coupled and slab ocean runs, respectively), relative to preindustrial values, in each of these configurations to quadrupling and doubling of $\mathrm{CO}_{2}$ concentrations. We use the abrupt $4 \times \mathrm{CO}_{2}$ experiment in order to qualitatively validate the CESM1 results, and the abrupt $2 \times \mathrm{CO}_{2}$ experiment to validate the results of previous studies.

\section{DATA AVAILABILITY}

The data used in the manuscript is publicly available for CMIP5 data (https://esgfnode.llnl.gov/projects/cmip5/), CESM LE (http://www.cesm.ucar.edu/), NSIDC (https:// nsidc.org), and HadCRUT4 (https://crudata.uea.ac.uk/cru/data/temperature//nsidc. org). The SOM LE and NOM LE data is available upon request from rei. chemke@weizmann.ac.il.

\section{CODE AVAILABILITY}

Any codes used in the manuscript are available upon request from rei. chemke@weizmann.ac.il.

Received: 17 April 2021; Accepted: 13 September 2021; Published online: 08 October 2021

\section{REFERENCES}

1. Stocker, T. F. et al. Climate Change 2013: The Physical Science Basis. Contribution of Working Group I to the Fifth Assessment Report of the Intergovernmental Panel on Climate Change (Cambridge Univ. Press, 2013).

2. Serreze, M. C., Barrett, A. P., Stroeve, J. C., Kindig, D. N. \& Holland, M. M. The emergence of surface-based Arctic amplification. Cryosphere 3, 11-19 (2009).

3. Serreze, M. C. \& Barry, R. G. Processes and impacts of Arctic amplification: a research synthesis. Glob. Planet. Chang. 77, 85-96 (2011).

4. Gillett, N. P. et al. Attribution of polar warming to human influence. Nat. Geosci. 1, 750-754 (2008).

5. Jones, G. S., Stott, P. A. \& Christidis, N. Attribution of observed historical nearsurface temperature variations to anthropogenic and natural causes using CMIP5 simulations. J. Geophys. Res. 118, 4001-4024 (2013).

6. Stroeve, J. C. et al. Trends in Arctic sea ice extent from CMIP5, CMIP3 and observations. Geophys. Res. Lett. 39, L16502 (2012).

7. Screen, J. A. \& Simmonds, I. The central role of diminishing sea ice in recent Arctic temperature amplification. Nature 464, 1334-1337 (2010).

8. Peings, Y. \& Magnusdottir, G. Response of the Wintertime Northern Hemisphere atmospheric circulation to current and projected Arctic sea ice decline: a numerical study with CAM5. J. Clim. 27, 244-264 (2014).

9. Deser, C., Tomas, R. A. \& Sun, L. The role of ocean-atmosphere coupling in the zonalmean atmospheric response to Arctic sea ice loss. J. Clim. 28, 2168-2186 (2015).
10. Sun, L., Deser, C. \& Tomas, R. A. Mechanisms of stratospheric and tropospheric circulation response to projected Arctic sea ice loss. J. Clim. 28, 7824-7845 (2015).

11. Deser, C., Sun, L., Tomas, R. A. \& Screen, J. Does ocean coupling matter for the northern extratropical response to projected Arctic sea ice loss? Geophys. Res. Lett. 43, 2149-2157 (2016).

12. Oudar, T. et al. Respective roles of direct GHG radiative forcing and induced Arctic sea ice loss on the northern hemisphere atmospheric circulation. Clim. Dyn. 49, 3693-3713 (2017).

13. Smith, D. M. et al. Atmospheric response to Arctic and Antarctic sea ice: the importance of ocean-atmosphere coupling and the background state. J. Clim. 30, 4547-4565 (2017)

14. Tomas, R. A., Deser, C. \& Sun, L. The role of ocean heat transport in the global climate response to projected Arctic sea ice loss. J. Clim. 29, 6841-6859 (2016).

15. Wang, K., Deser, C., Sun, L. \& A., T. R. Fast response of the tropics to an abrupt loss of arctic sea ice via ocean dynamics. Geophys. Res. Lett. 45 (2018).

16. Screen, J. A. et al. Consistency and discrepancy in the atmospheric response to Arctic sea-ice loss across climate models. Nat. Geosci. 11, 155-163 (2018).

17. Chemke, R., Polvani, L. M. \& Deser, C. The effect of Arctic sea ice loss on the Hadley circulation. Geophys. Res. Lett. 46, 963-972 (2019).

18. Hwang, Y., Frierson, D. M. W. \& Kay, J. E. Coupling between Arctic feedbacks and changes in poleward energy transport. Geophys. Res. Lett. 38, L17704 (2011).

19. Chemke, R. \& Polvani, L. M. Linking polar amplification and eddy heat flux trends. npj Clim. Atmos. Sci. 3, 8 (2020).

20. Deser, C. \& Teng, H. Evolution of Arctic sea ice concentration trends and the role of atmospheric circulation forcing, 1979-2007. Geophys. Res. Lett. 35, L02504 (2008).

21. Lee, S., Gong, T., Johnson, N., Feldstein, S. B. \& Pollard, D. On the possible link between tropical convection and the northern hemisphere Arctic surface air temperature change between 1958 and 2001. J. Clim. 24, 4350-4367 (2011).

22. Luo, B., Luo, D., Wu, L., Zhong, L. \& Simmonds, I. Atmospheric circulation patterns which promote winter Arctic sea ice decline. Env. Res. Lett. 12, 054017 (2017).

23. Woods, C. \& Caballero, R. The role of moist intrusions in winter Arctic warming and sea ice decline. J. Clim. 29, 4473-4485 (2016).

24. Cho, D. \& Kim, K. Role of Ural blocking in Arctic sea ice loss and its connection with Arctic warming in winter. Clim. Dyn. 56, 1571-1588 (2021).

25. Screen, J. A. \& Simmonds, I. Increasing fall-winter energy loss from the Arctic Ocean and its role in Arctic temperature amplification. Geophys. Res. Lett. 37, L16707 (2010).

26. Screen, J. A. \& Francis, J. A. Contribution of sea-ice loss to Arctic amplification is regulated by Pacific Ocean decadal variability. Nat. Clim. Change 6, 856-860 (2016).

27. Dai, A., Luo, D., Song, M. \& Liu, J. Arctic amplification is caused by sea-ice loss under increasing CO2. Nat. Commun. 10, 121 (2019).

28. Graversen, R. G. \& Wang, M. Polar amplification in a coupled climate model with locked albedo. Clim. Dyn. 33, 629-643 (2009).

29. Pithan, F. \& Mauritsen, T. Arctic amplification dominated by temperature feedbacks in contemporary climate models. Nat. Geosci. 7, 181-184 (2014).

30. Park, D. R., Lee, S. \& Feldstein, S. B. Attribution of the recent winter sea ice decline over the Atlantic Sector of the Arctic ocean. J. Clim. 28, 4027-4033 (2015).

31. Lee, S., Gong, T., Feldstein, S. B., Screen, J. A. \& Simmonds, I. Revisiting the cause of the 1989-2009 Arctic surface warming using the surface energy budget: downward infrared radiation dominates the surface fluxes. Geophys. Res. Lett. 44, 10,654-10,661 (2017).

32. Feldl, N., Po-Chedley, S., Singh, H. K. A., Hay, S. \& Kushner, P. J. Sea ice and atmospheric circulation shape the high-latitude lapse rate feedback. npj Clim. Atmos. Sci. 3, 41 (2020).

33. Holland, M. M. \& Bitz, C. M. Polar amplification of climate change in coupled models. Clim. Dyn. 21, 221-232 (2003).

34. Mahlstein, I. \& Knutti, R. Ocean heat transport as a cause for model uncertainty in projected Arctic warming. J. Clim. 24, 1451-1460 (2011).

35. Spielhagen, R. F. et al. Enhanced Modern Heat Transfer to the Arctic by Warm Atlantic Water. Science 331, 450 (2011).

36. Nummelin, A., Li, C. \& Hezel, P. J. Connecting ocean heat transport changes from the midlatitudes to the Arctic Ocean. Geophys. Res. Lett. 44, 1899-1908 (2017).

37. Singh, H. A., Rasch, P. J. \& Rose, B. E. J. Increased ocean heat convergence into the high latitudes with $\mathrm{CO}_{2}$ doubling enhances polar-amplified warming. Geophys. Res. Lett. 44, 10 (2017).

38. Årthun, M., Eldevik, T. \& Smedsrud, L. H. The role of Atlantic heat transport in future Arctic winter sea ice loss. J. Clim. 32, 3327-3341 (2019).

39. Goosse, H. et al. Quantifying climate feedbacks in polar regions. Nat. Commun. 9, 1919 (2018)

40. Kay, J. E. et al. The influence of local feedbacks and northward heat transport on the equilibrium Arctic climate response to increased greenhouse gas forcing. J. Clim. 25, 5433-5450 (2012).

41. Bitz, C. M., Gent, P. R., Woodgate, R. A., Holland, M. M. \& Lindsay, R. The influence of sea ice on ocean heat uptake in response to increasing $\mathrm{CO}_{2}$. J. Clim. 19, 2437 (2006). 
42. Middlemas, E. A., Kay, J. E., Medeiros, B. M. \& Maroon, E. A. Quantifying the influence of cloud radiative feedbacks on Arctic surface warming using cloud locking in an earth system model. Geophys. Res. Lett. 47, e89207 (2020).

43. Taylor, K. E., Stouffer, R. J. \& Meehl, G. A. An overview of CMIP5 and the experiment design. Bull. Am. Meteor. Soc. 93, 485-498 (2012).

44. Hurrell, J. W. et al. The community earth system model: a framework for collaborative research. Bull. Am. Meteor. Soc. 94, 1339-1360 (2013).

45. Deser, C., Phillips, A., Bourdette, V. \& Teng, H. Uncertainty in climate change projections: the role of internal variability. Clim. Dyn. 38, 527-546 (2012).

46. Kay, J. E. et al. The Community Earth System Model (CESM) large ensemble project: a community resource for studying climate change in the presence of internal climate variability. Bull. Am. Meteor. Soc. 96, 1333-1349 (2015).

47. Morice, C. P., Kennedy, J. J., Rayner, N. A. \& Jones, P. D. Quantifying uncertainties in global and regional temperature change using an ensemble of observational estimates: the HadCRUT4 data set. J. Geophys. Res. 117, D08101 (2012).

48. Barnhart, K. R., Miller, C. R., Overeem, I. \& Kay, J. E. Mapping the future expansion of Arctic open water. Nat. Clim. Change 6, 280-285 (2016).

49. Jahn, A., Kay, J. E., Holland, M. M. \& Hall, D. M. How predictable is the timing of a summer ice-free Arctic? Geophys. Res. Lett. 43, 9113-9120 (2016).

50. England, M. R., Jahn, A. \& Polvani, L. M. Nonuniform contribution of internal variability to recent Arctic sea ice loss. J. Clim. 32, 4039-4053 (2019).

51. Fetterer, F., Knowles, K., Meier, W. N., Savoie, M. \& Windangel, A. K. Sea Ice Index, Version 3. Sea ice extent (2017). Boulder, Colorado USA. NSIDC: National Snow and Ice Data Center. Accessed 27 Oct 2019.

52. Hansen, J. et al. Climate response times: dependence on climate sensitivity and ocean mixing. Science 229, 857-859 (1985).

53. Gregory, J. M. et al. A new method for diagnosing radiative forcing and climate sensitivity. Geophys. Res. Lett. 31, L03205 (2004).

54. Bitz, C. M. et al. Climate sensitivity of the Community Climate System Model, Version 4. J. Clim. 25, 3053-3070 (2012).

55. Kelley, M. et al. GISS-E2.1: configurations and climatology. J. Adv. Mod. Earth Syst. 12, e2019MS002025 (2020).

\section{ACKNOWLEDGEMENTS}

We are grateful to Ivan Mitevski for analyzing the GISS ModelE data. R.C. was supported by the Israeli Science Foundation Grant 906/21. L.M.P. is grateful for the continued support of the U.S. Nat. Sci. Foundation. J.E.K. was funded by NSF Award $\# 1554659$.

\section{AUTHOR CONTRIBUTIONS}

R.C. conducted, downloaded, and analyzed the data and together with L.M.P., J.E.K. and C.O. discussed and wrote the paper.

\section{COMPETING INTERESTS}

The authors declare no competing interests.

\section{ADDITIONAL INFORMATION}

Supplementary information The online version contains supplementary material available at https://doi.org/10.1038/s41612-021-00204-8.

Correspondence and requests for materials should be addressed to Rei Chemke.

Reprints and permission information is available at http://www.nature.com/ reprints

Publisher's note Springer Nature remains neutral with regard to jurisdictional claims in published maps and institutional affiliations.

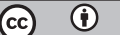

Open Access This article is licensed under a Creative Commons Attribution 4.0 International License, which permits use, sharing, adaptation, distribution and reproduction in any medium or format, as long as you give appropriate credit to the original author(s) and the source, provide a link to the Creative Commons license, and indicate if changes were made. The images or other third party material in this article are included in the article's Creative Commons license, unless indicated otherwise in a credit line to the material. If material is not included in the article's Creative Commons license and your intended use is not permitted by statutory regulation or exceeds the permitted use, you will need to obtain permission directly from the copyright holder. To view a copy of this license, visit http://creativecommons. org/licenses/by/4.0/.

(c) The Author(s) 2021 